\title{
DESKRIPSI PENGGUNAAN ALAT PELINDUNG DIRI (APD) PADA PETUGAS CLEANING SERVICE RSUD KRT SETJONEGORO KABUPATEN WONOSOBO TAHUN 2016
}

\author{
Ida Khusiana $^{1)}$, Teguh Widiyanto ${ }^{2)}$ \\ Jurusan Kesehatan Lingkungan Politeknik Kesehatan Semarang, \\ Jl. Raya Baturaden KM 12 Purwokerto,Indonesia
}

\begin{abstract}
Abstrak
Rumah sakit termasuk dalam kriteria tempat kerja dengan berbagai ancaman berbahaya yang berdampak pada kesehatan. Bukan hanya pada petugas rumah sakit tetapi juga pasien dan pengunjung rumah sakit. Sudah seharusnya pihak rumah sakit menerapkan upaya Keselamatan dan Kesehatan Kerja (K3), khususnya penggunaan Alat Pelindung Diri (APD) pada petugas cleaning service saat melakukan pekerjaannya.Metode penelitian yang digunakan adalah deskriptif yaitu dengan menggambarkan keadaan penggunaan alat pelindung diri pada petugas cleaning service di RSUD KRT. Setjonegoro. Subjek penelitian adalah alat pelindung diri pada petugas cleaning service di RSUD KRT. Setjonegoro. Jumlah petugas yang dijadikan responden berjumlah 32 orang. Cara pengumpulan data yaitu wawancara kepada para petugas dan observasi. Jenis APD yang disediakan yaitu pakaian kerja, sepatu kerja, masker, dan sarung tangan. Masing-masing APD berjumlah 32 buah dan disediakan untuk semua petugas cleaning service. Semua APD yang disediakan dalam kondisi baik. Penggunaan APD sesuai dengan Aktivitas kerja yang dilakukan petugas. Belum diadakanya pelatiha penggunaan APD. Pengawasan dan penegakan aturan dilakuakan oleh pengawas cleaning service. Bahaya dan risiko yang ada pada petugas clesning service adalah mengalami penyakit akibat kerja dan kecelakaan kerja.Disimpulkan dari penelitian ini adalah jenis APD yang disediakan sudah sesuai dengan jenis pekerjaan dan jumlah petugas, APD dalam keadaan baik, pengawasan dan pemberlakuan aturan diterapkan oleh pengawas cleaning service sehingga bahaya dan risiko yang ada pada petugas cleaning service antara lain mengalami penyakit akibat kerja dan kecelakan kerja dapat dicegah.
\end{abstract}

Kata kunci : APD-Ceaning service

\begin{abstract}
Hospitals included in the criteria for the workplace whit a variety of malicious threats that impact on health. Not only on hospital personnel but also patients and hospital visitors. Should the hospital implemen occupational safety and health efforts (SHE), in particular the use of personal protective equipments (PPE) at the cleaning service while doing his job. The research method used is descriptive by describing the state of the use of personal protective equipment in officers cleaning service RSUD KRT Setjonegoro research subjects are personal protective equipment officer cleaning service. Number of office as respondents amounted to 32 people. A data collectiom were interviews and observation to the office. PPE types are provide, namely work clothing. Work boots, masks and gloves. Each PPE amouned to 32 pieces and is provided for all officer cleaning service. All PPE supplied in good condition. The use of PPE in accordence with the work activities undertaken officers. Not been held for training in the use of PPE. Surveilance and enforcement is done by supervisior cleaning service. Harzard and risk placed on the cleaning service issuffered occupational diseases and accidents. Concluted of the research is the type of PPE that is provide is in accordance with the typeof workes and the number of officers, PPE is in good condition, supervision and enforcement of the rules applied by the supervisory cleaning sevice so that hazardand risk of the cleaning service,among others suffered occupational diseases and accidents.
\end{abstract}

Keywords $\quad$ : Cleaning Service PPE, Hospital KRT. Setjonegoro

\section{I.PENDAHULUAN}

Sejalan dengan ilmu pengetahuan dan teknologi, peralatan serta cara kerja organisasi baik perusahaan maupun instansi pemerintah lainya, Keselamatan dan Kesehatan Kerja (K3) memegang peranan penting dalam mencegah terjadinya berbagai resiko kecelakaan kerja seperti ledakan, kebakaran, maupun penyakit yang timbul akibat pekerjaan yang memiliki

1) Email : idakhusiana@gmail.com

2) Email : teguhwidiyanto007@gmail.com tingkat pengaruh cukup besar dalam hal menurunnya produktivitas kerja.

Pelaksanaan Keselamatan dan Kesehatan Kerja (K3) adalah salah satu bentuk upaya untuk menciptakan tempat kerja yang aman, sehat, bebas dari pencemaran lingkugan, sehingga dapat mengurangi dan atau bebas dari kecelakaan kerja dan penyakit akibat kerja yang pada akhirnya dapat meningkat efisiensi dan produktivitas kerja. 
Penyakit Akibat Kerja (PAK) dan Kecelakaan Kerja (KK) di kalangan petugas kebersihan (Cleanning service) di Indonesia belum terekam dengan baik. Jika kita pelajari angka kecelakaan dan penyakit akibat kerja di beberapa negara maju (dari beberapa pengamatan) menunjukan kecenderungan peningkatan prevalensi. Sebagai faktor penyebab terjadinya kecelakan kerja, salah satunya karena kurangnya pengetahuan dari seorang petugas kebersihan (Cleanning service) tentang keselamatan dan kesehatan kerja.

Dalam penjelasan undang-undang nomor 36 tahun 2009 tentang Kesehatan telah mengamanatkan antara lain, setiap tempat kerja harus melaksanakan upaya kesehatan kerja, agar tidak terjadi gangguan kesehatan pada pekerja, keluarga, masyarakat dan lingkungan disekitarnya.

Dalam bekerja, keselamatan dan kesehatan kerja (K3) merupakan faktor yang sangat penting untuk diperhatikan karena seseorang yang mengalami sakit atau kecelakaan dalam bekerja akan berdampak pada diri, keluarga dan lingkungannya. Dalam UndangUndang Nomor 23 Tahun 2003 tentang Ketenagakerjaan , Pasal 23 dinyatakan bahwa upaya Keselamatan dan Kesehatan Kerja (K3) harus diselenggarakan di semua tempat kerja, khususnya tempat kerja yang mempunyai risiko bahaya kesehatan, mudah terjangkit penyakit atau mempunyai karyawan paling sedikit 100 orang. Jika memperhatikan isi dari pasal di atas maka jelaslah bahwa Rumah Sakit (RS) termasuk ke dalam kriteria tempat kerja dengan berbagai ancaman bahaya yang dapat menimbulkan dampak kesehatan, tidak hanya terhadap para pelaku langsung yang bekerja di rumah sakit, tapi juga terhadap pasien maupun pengunjung RS. Sehingga sudah seharusnya pihak pengelola rumah sakit menerapkan upaya-upaya K3 di RS, khususnya penggunaan Alat Pelindung Diri (APD) pada petugas cleanning service saat melakukan pekerjaannya.

Potensi bahaya di RS, selain penyakit-penyakit infeksi juga ada potensi bahaya-bahaya lain yang mempengaruhi situasi dan kondisi di RS, yaitu kecelakaan (peledakan, kebakaran, kecelakaan yang berhubungan dengan instalasi listrik, dan sumbersumber cidera lainnya), radiasi, bahan-bahan kimia yang berbahaya, gas-gas anastesi, infeksi nosokomial, gangguan psikososial dan ergonomi.

Rumah sakit merupakan salah satu institusi pelayanan umum yang memiliki kompleksitas yang cukup tinggi, baik dari segi ketenagaan, pelayanan, peralatan dan lain-lain. Di rumah sakit juga ada banyak sumber-sumber bahaya seperti bahaya radiasi, kontaminasi zat berbahaya dan beracun, selain itu juga penyakit akibat kerja dan kecelakaa kerja. Hal ini jika tidak di antisipasi dengan baik dan dikelola secara profesional dengan memperhatikan normanorma keselamatan dan kesehatan kerja akan menyebabkan timbulnya masalah yang berakibat pada kerugian baik kerugian material maupun non material di pihak rumah sakit, masyarakat pengguna jasa rumah sakit maupun karyawan yang bekerja di rumah sakit itu sendiri.

Dalam undang-undang No 1 tahun 1970 tentang keselamatan dan pencegahan kecelakaan kerja dijelaskan bahwa perusahaan wajib melindungi keselamatan kerja karyawannya yaitu dengan memberi penjelasan kepada tenaga kerja tentang kondisi dan bahaya tempat kerja, alat pelindung diri bagi tenaga kerja serta cara dan sikap yang aman dalam melaksanakan pekerjaan

Analisis kecelakaan kerja memperlihatkan bahaya untuk setiap kecelakaan kerja ada faktor penyebabnya. Sebab-sebab tersebut bersumber kepada alat-alat mekanik dan lingkungan serta kepada manusianya itu sendiri. Untuk mencegah kecelakaan, penyebab-penyebab ini harus dihilangkan. $85 \%$ dari sebab-sebab kecelakaan adalah faktor manusia. Maka dari itu usaha-usaha keselamatan selain ditunjukkan kepada tehnik mekanik juga harus memperhatikan secara khusus aspek manusiawi (Suma’ar, 1989 h:29).

Di RSUD KRT Setjonegoro banyak cleaning servis yang tidak memakai APD sehingga dapat berisiko mengalami kecelakan kerja dan penyakit akibat kerja karena di rumah sakit mempunyai amcaman bahaya yang sangat berisiko tinggi menularkan berbagai penyakit.

Berdasarkan uraian di atas, penulis tertarik untuk membahas deskripsi penggunaan Alat Pelindung Diri (APD) pada petugas cleaning service di RSUD KRT Setjonegoro Kabupaten Wonosobo tahun 2016

\section{II.BAHAN DAN METODE}

Bahan yang digunakan dalam penelitian ini adalah menggunakan Cheklist dan Kuisioner, pengumpulan data dilakuksn dengan cara wawancara dan observasi. Pengumpulan data, jenis data yang diperoleh berupa Data Umum (gambaran umum RSUD KRT. Setjonegoro, petugas, umur, pendidikan, massa kerja). Data khusus ( jumlah, jenis, dan kondisi APD, kesesuaian APD, penggunaan APD, penggunaan $A P D$, pengawasan, penegakan aturan bahaya tidak menggunakan APD, dan risiko tidak menggunakan APD). Metode yang digunakan adalah deskriptif yaitu untuk menggambarkan tentang penggunaan alat pelindung diri (APD) pada petugas cleaning service di RSUD KRT. Setjonegoro. Faktor utama terdiri dari petugas, umur, pendidikan, massa kerja. Faktor pendukung terdiri dari jumlah, jenis, dan kondisi APD, kesesuaian APD, penggunaan APD, penggunaan APD. Faktor pendorong terdiri dari pengawasan, penegakan aturan bahaya tidak menggunakan APD, dan risiko tidak menggunakan APD. Lokasi yang diambil untuk penelitian adalah RSUD KRT. Setjonegoro jalan Rumah Sakit No. 1 Wonosobo, Kecamatan Wonosobo, Kabupaten Wonosobo, Propinsi Jawa Tengah. Subjek penelitian adalah alat pelindung diri pada petugas cleaning 
service di RSUD KRT. Setjonegoro. Jumlah petugas yang dijadikan responden berjumlah 32 orang.

\section{III.HASIL DAN PEMBAHASAN}

Gambaran umum. Lokasi RSUD KRT. Setjonegoro berada dipusat keramaian tepatnya bersebelahan dengan pusat ekonomi yaitu pasar tradisional maupun modern (swalayan), pusat pemerintahan, pusat pendidikan dan dikelilingi oleh perkampungan yang padat. Posisi ini sangat strategis untuk pengembangan rumah sakit dalam fungsinya sebagai provider pelayanan kesehatan, utamanya sebagai fasilitas pelayanan kesehatan rujukan bagi sarana kesehatan di wilayah Kabupaten Wonosobo dan juga dari kabupaten lain yang berbatasan langsung dengan Wonosobo. RSUD KRT Setjonegoro Kabupaten Wonosobo terletak di jalan Jl. Rumah Sakit No. 1 Wonosobo, Jawa Tengah 56312 Phone: (0286) 320191 Fax: (0286) 323873, Kecamatan Wonosobo, Kabupaten Wonosobo, Provinsi Jawa Tengah. Secara geografis, RSUD KRT Setjonegoro Wonosobo memiliki batas-batas wilayah sebagai berikut :

a. Sebelah Timur : Pasar tradisional

b. Sebelah Selatan: Pemukiman penduduk

c. Sebelah Barat : Pemukiman penduduk

d. Sebelah Utara : Terminal angkutan umum

Gambaran petugas cleaning service di RSUD

KRT. Setjonegoro:

Tabel 4.4 Data jumlah petugas cleaning service berdasarkan umur di RSUD KRT Setjonegoro

\begin{tabular}{cccc}
\hline No & $\begin{array}{c}\text { Umur } \\
\text { Responden }\end{array}$ & $\begin{array}{c}\text { Jumlah } \\
\text { (Org) }\end{array}$ & Presentare (\%) \\
\hline 1 & $20-30$ & 23 & 71,875 \\
2 & $31-40$ & 7 & 21,875 \\
3 & $41-50$ & 2 & 6,25 \\
\hline \multicolumn{2}{c}{ Jumlah } & 32 & 100 \\
\hline
\end{tabular}

Tabel 4.5 Data jumlah petugas cleaning service berdasarkan tingkat pendidikan di RSUD KRT Setjonegoro

\begin{tabular}{llcc}
\hline No & \multicolumn{1}{c}{ Tingkat pendidikan } & $\begin{array}{c}\text { Jumlah } \\
\text { (Org) }\end{array}$ & $\begin{array}{c}\text { Presentasi } \\
(\mathbf{\% )})\end{array}$ \\
\hline 1 & Lulusan SD & 0 & 0 \\
2 & Lulusan SMP & 0 & 0 \\
3 & $\begin{array}{l}\text { Lulusan SMA/ SMK/ } \\
\text { SEDERAJAT }\end{array}$ & 32 & 100 \\
4 & $\begin{array}{l}\text { Perguruan Tinggi } \\
\text { Jumlah }\end{array}$ & 0 & 0 \\
\hline
\end{tabular}

Tabel 4.6 Data jumlah petugas cleaning service berdasarkan massa kerja di RSUD KRT Setjonegoro

\begin{tabular}{cccc}
\hline No & Massa Kerja & $\begin{array}{c}\text { Jumlah } \\
\text { (Org) }\end{array}$ & Presentasi (\%) \\
\hline 1 & $0-2$ & 14 & 43,75
\end{tabular}

\begin{tabular}{cccc}
2 & $3-5$ & 18 & 56,25 \\
\hline Jumlah & 32 & 100 \\
\hline
\end{tabular}

Tabel 4.7 Data jumlah APD menurut jenis dan kondisi pada petugascleaning service di RSUD KRT Setjonegoro

\begin{tabular}{|c|c|c|c|c|c|c|c|}
\hline \multirow{2}{*}{ No } & \multirow{2}{*}{$\begin{array}{c}\text { Jenis Alat } \\
\text { Pelindung } \\
\text { Diri }\end{array}$} & \multicolumn{4}{|c|}{ Kondisi } & \multirow{2}{*}{$\begin{array}{c}\text { Jumlah } \\
\text { (Buah) }\end{array}$} & \multirow{2}{*}{$\%$} \\
\hline & & Baik & $\%$ & Rusak & $\%$ & & \\
\hline 1 & Pakaian kerja & 32 & 100 & 0 & 0 & 32 & 100 \\
\hline 2 & Sepatu kerja & 32 & 100 & 0 & 0 & 32 & 100 \\
\hline 3 & Masker & 32 & 100 & 0 & 0 & 32 & 100 \\
\hline 4 & Sarung tangan & 32 & 100 & 0 & 0 & 32 & 100 \\
\hline
\end{tabular}

Tabel 4.8 Data pemakaian penggunaan APD dan kesesuaian APD menurut aktivitas kerja oleh petugas cleaning service di RSUD KRT Setjonegoro.

\begin{tabular}{|c|c|c|c|c|c|c|c|c|c|c|c|c|c|}
\hline \multirow{3}{*}{ No } & \multirow{3}{*}{$\begin{array}{c}\text { Aktivitas } \\
\text { Kerja }\end{array}$} & \multicolumn{12}{|c|}{ Hasil pemakaian APD } \\
\hline & & \multicolumn{3}{|c|}{$\mathbf{A}$} & \multicolumn{3}{|c|}{ B } & \multicolumn{3}{|c|}{$\mathbf{C}$} & \multicolumn{3}{|c|}{ D } \\
\hline & & $\sqrt{ }$ & $\not$ & $\sum$ & $\sqrt{ }$ & $\neq$ & $\sum$ & $\sqrt{ }$ & $\neq$ & $\sum$ & $\sqrt{ }$ & $\neq$ & $\sum$ \\
\hline 1 & Menyapu & 8 & - & 8 & 8 & - & 8 & - & 8 & 8 & - & 8 & 8 \\
\hline 2 & Mengepel & 8 & - & 8 & 8 & - & 8 & - & 8 & 8 & - & 8 & 8 \\
\hline 3 & $\begin{array}{l}\text { Membuang } \\
\text { sampah }\end{array}$ & 2 & - & 2 & 2 & - & 2 & 2 & - & 2 & 2 & - & 2 \\
\hline 4 & $\begin{array}{l}\text { Membersihkan } \\
\text { kaca }\end{array}$ & 8 & - & 8 & 8 & - & 8 & - & 8 & 8 & 8 & - & 8 \\
\hline 5 & $\begin{array}{l}\text { Membersihkan } \\
\text { kamar mandi }\end{array}$ & 6 & - & 6 & 6 & - & 6 & 6 & - & 6 & - & 6 & 6 \\
\hline
\end{tabular}

$\mathrm{A}=$ pakaian kerja

$\mathrm{B}=$ sepatu kerja

$\mathrm{C}=$ masker

$\mathrm{D}=$ sarung tangan

$\sqrt{ }=$ jumlah petugas yang memakai APD

$\neq \quad=$ jumlah petugas yang tidak memakai APD

$\Sigma=$ jumlah APD yang disediakan

1. Menurut Umur Petugas

Umur petugas cleaning service di RSUD KRT Setjonegoro kisaran antara 20 tahun hingga 50 tahun. Jumlah petugas umur 20 hingga 30 tahun adalah 23 orang, jumlah petugas umur 3140 tahun adalah 7 orang, jumlah petugas umur 41-50 tahun adalah 2 orang.

2. Menurut Tingkat Pendidikan Petugas

Tingkat pendidikan petugas cleaning service di RSUD KRT Setjonegoro seluruhnya lulusan SMA/SMK/SEDERAJAT berjumlah 32 orang.

3. Menurut Massa Kerja Petugas

Massa kerja petugas cleaning service di RSUD KRT Setjonegoro antara 0 hingga 5 tahun karena sistem kerja yang digunakan adalah sistem kontrak. Jumlah petugas menurut massa kerja 0-2 tahun adalah 14 orang, jumlah petugas menurut massa kerja 3-5 tahun adalah 18 orang.

4. Jumlah APD

Jumlah alat pelindung diri yang disediakan RSUD KRT Setjonegoro masing-masing berjumlah 32 buah. Alat pelindung diri yang ada 
dibagikan kepada semua para petugas cleaning service. Alat pelindung diri seperti masker, sarung tangan disediakan lebih dari jumlah petugas karena disediakan sebagai cadangan jika alat pelindung diri yang digunakan petugas rusak atau tidak layak digunakan dan disediakan bagi setiap petugas cleaning service.

5. Jenis APD

Alat pelindung diri yang disediakan RSUD KRT Setjonegoro berupa pakaian kerja, sepatu kerja, masker, sarung tangan.

a. Pakaian kerja

Pakaian kerja yang terbuat dari bahan sejenis katun berwarna orange dan biru sedangkan celana terbuat dari bahan drill berwarna hitam. Pakaian kerja berlengan pendek (sampai siku), longgar. Dengan menggunakan pakaian kerja pada saat bekerja, gerakan dalam bekerja menjadi leluasa.

b. Sepatu kerja

Jenis sepatu yang disediakan adalah sepatu kerja yang terbuat dari karet berwarna hitam (sepatu boot). Sepatu tersebut dapat melindungi petugas dari benda tajam atau menginjak benda tajam. Sepatu kerja dibagikan kepada setiap tenaga kerja, tetapi beberapa petugas bertugas didalam ruangan maka petugas menggunakan sepatu pantofel.

c. Masker

Masker yang disediakan oleh pihak Rumah Sakit adalah masker yang hanya sekali pakai dengan disertai tali untuk mempermudah pemakaian pada saat bekerja. Apabila kondisi masker sudah rusak atau layak digunakan lagi maka petugas dapat meminta yang baru kepada pemimpin cleaning service.

d. Sarung tangan

Sarung tangan yang disediakan oleh pihak rumah sakit terbuat dari karet berwarna orange. Apabila kondisi sarung tangan sudah rusak atau layak digunakan lagi maka petugas dapat meminta yang baru kepada pemimpin cleaning service.

6. Kondisi penggunaan APD

Alat pelindung diri yang disediakan seperti pakaian kerja, sepatu kerja, masker, sarung tangan semuanya dalam kondisi baik dan layak digunakanp oleh petugas.

7. Menurut kesesuaian kondisi penggunaan APD

Dalam kesesuaian penggunaan APD pada para petugas tidak menggunakan APD pada saat melakukan aktivitas mengepel dan menyapu. Alasan petugas tidak menggunakan APD tersebut karena para petugas tidak nyaman menggunakanya. Sebaiknya petugas menggunakan APD pada saat mengepel, menyapu, dam membersihkan kamar mandi agar meminimasisir terjadinya kecelakaan kerja,
Setelah petugas cleaning service selesai menggunakan alat pelindung diri petugas langsung membuang masker dan sarung tangan ke tempat sampah infeksius. Karena masker dan sarung tangan yang digunakan hanya sekali pakai.

8. Menurut pelatihan penggunaan alat pelindung diri

Di RSUD KRT. Setjonegoro tidak ada pelatihan penggunaan APD oleh menejemen Rumah Sakit. Sebaiknya pengawas dan Rumah Sakit mengadakan pelatihan tentang penggunaan alat pelindung diri agar para petugas cleaning service tahu jenis, cara penggunaan alat pelindung diri dengan baik dan petugas tahu masing-masing kegunaan alat pelindung diri.

9. Menurut pengawasan dan penegakan peraturan pemakaian APD

Pengawasan dan penegakan peraturan pengunaan APD dilakukan oleh pemimpin cleaning service di setiap ruangan dari masing masing shiff yang dilakukan setiap jam kerja. Pengawasan yang dilakukan di RSUD KRT. Setjonegoro dengan melakukan pemeriksaan secara berkala, dan mengecek petugas dalam pemakaian APD secara lengkap sebelum dan sesudah bekerja, jika ada petugas yang tidak mematuhi peraturan, maka pemimpin cleaning service berhak memberikan peringatan secara lisan maupun tertulis

Tabel 4.9 Data bahaya dan risiko pada saat melakukan aktivitas kerja oleh petugas cleaning service di RSUD KRT Setjonegoro.

\begin{tabular}{|c|c|c|c|c|}
\hline No & $\begin{array}{l}\text { Potensi } \\
\text { bahaya }\end{array}$ & Lokasi & $\begin{array}{c}\text { Aktivitas yang } \\
\text { berisiko }\end{array}$ & Risiko \\
\hline 1 & Debu & $\begin{array}{l}\text { Seluruh } \\
\text { ruangan } \\
\text { RSUD KR } \\
\text { Setjonegorc }\end{array}$ & $\begin{array}{l}\text { Menyapu } \\
\text { di } \\
\text { 2T. } \\
\text { o }\end{array}$ & $\begin{array}{l}\text { ISPA dan } \\
\text { Iritasi mata }\end{array}$ \\
\hline 2 & Terpeleset & $\begin{array}{l}\text { Seluruh } \\
\text { ruangan } \\
\text { RSUD KR } \\
\text { Setjonegorc }\end{array}$ & $\begin{array}{l}\text { Mengepel } \\
\text { di } \\
\mathrm{T} \text {. }\end{array}$ & $\begin{array}{l}\text { Patah } \\
\text { tulang }\end{array}$ \\
\hline 3 & $\begin{array}{l}\text { Infeksi } \\
\text { nosokomial }\end{array}$ & $\begin{array}{l}\text { Seluruh } \\
\text { ruangan } \\
\text { RSUD KR' } \\
\text { Setjonegoro }\end{array}$ & \begin{tabular}{ll}
\multicolumn{1}{l}{ Pengumpulan } & $\mathrm{I}$ \\
disampah & $\mathrm{i}$ \\
$\mathrm{T}$. & $\mathrm{I}$ \\
$\mathrm{O}$ &
\end{tabular} & $\begin{array}{l}\text { Penyakit } \\
\text { infeksi } \\
\text { nosokomial }\end{array}$ \\
\hline 4 & Terjatuh & $\begin{array}{l}\text { Seluruh } \\
\text { ruangan } \\
\text { RSUD KR' } \\
\text { Setjonegoro }\end{array}$ & $\begin{array}{l}\text { Membersihkan } \\
\text { dikaca jendela } \\
\text { T. } \\
\text { o }\end{array}$ & $\begin{array}{l}\text { Patah } \\
\text { tulang }\end{array}$ \\
\hline 5 & $\begin{array}{l}\text { Terkena } \\
\text { desinfektan }\end{array}$ & $\begin{array}{l}\text { Seluruh } \\
\text { ruangan } \\
\text { RSUD KR' } \\
\text { Setjonegoro }\end{array}$ & $\begin{array}{l}\text { Membersihkan I } \\
\text { dikamar mandi“ } \\
\text { T.dan mengepel } \\
\text { o }\end{array}$ & $\begin{array}{l}\text { Iritasi } \\
\text { j“sedang” } \\
\text { pada kulit }\end{array}$ \\
\hline
\end{tabular}

Sumber : Wendy S, 1988 (The Hazard Of Hospital

Work 
10. Menurut bahaya dan risiko saat melakukan aktivitas kerja

Potensi bahaya yang ada di RSUD KRT. Setjonegoro dapat mengakibatkan penyakit akibat kerja dan kecelakaan kerja seperti debu pada saat menyapu risiko yang dapat terjadi ISPA dan iritasi pada bagian mata, terpleset dapat saat mengepel, risiko yang dapat terjadi patah tulang dapat petugas cleaning service, infeksi nosokomial pada saat petugas cleaning service mengumpulkan sampah medis, petugas terjatuh pada saat petugas melakukan aktivitas membersihkan kaca jendela risiko yang dapat terjadi patah tulang, kulit petugas terkena desinfeksi pada saat membersihkan kamar mandi risiko yang dapat terjadi iritasi “sedang” seperti kulit melepuh dan kulit terasa panas. Sebaiknya petugas menggunakan alat pelindung (APD) yang telah disediakan oleh Rumah Sakit untuk mengurangi potensi bahaya dan risiko yang ada.

\section{IV.KESIMPULAN}

Jenis APD yang disediakan sudah sesuai dengan jenis pekerjaan dan jumlah petugas, APD dalam keadaan baik, pengawasan dan pemberlakuan aturan diterapkan oleh pengawas cleaning service sehingga bahaya dan risiko yang ada pada petugas cleaning service antara lain mengalami penyakit akibat kerja dan kecelakan kerja dapat dicegah.

\section{DAFTAR PUSTAKA}

Aprilian Siburian, 2012, Gambaran Penggunaan Alat Pelindung Diri (APD) Terhadap Keselamatan Kerja Perawat IGD RSUD Pasar Rebo Tahun 2012, Karya Tulis, Depok: Fakultas Kesehatan Masyarakat Universitas Indonesia Program Studi Sarjanah Kesehatan Masyarakat Permintaan Kebidanan Komunitas Depok.

Dahlima Febrianty, 2012, Gambaran Penggunaan Alat Pelindung Diri Oleh Bidan Di Desa Pada Waktu Melakukan Pertolongan Persalinan Di Rumah Dan Faktor-Faktor Yang Mempengaruhi Di Wilayah Kerja Dinas kesehatan kabupaten Balangan Tahun 2012, Karya Tulis, Depok: Fakultas
Kesehatan Masyarakat Universitas Indonesia Program Studi Sarjanah Kesehatan Masyarakat Permintaan Kebidanan Komunitas Depok.

Ferry Andriana, 2008, Studi Penggunaan Alat Pelindung Diri (APD) Pada Pekerja Industri Daur Ulang Plastik Bekas Desa Banjarparakan Kecamatan Rawalo Kabupaten Banyumas Tahun 2008, Karya Tulis, Purwokerto:Kementerian Kesehatan RI Politeknik Kesehatan Semarang Jurusan kesehatan Lingkungan Purwokerto.

http://www.konsultank3.com/training/jurnalpenelitian-apd-pada-petugas-cleaningservice-di-rumah-sakit-pdf.html/page/3( $d i$ akses pada tanggal 29 Desember 2015 )

http://alat2kesehatan.com/jenis-alat-pelindung-diridi-rumah-sakit.php(di akses pada tanggal 29 Desember 2015)

http://www.prashetyaquality.co.id/2013/03/penerapan -k3-pada-cleaning service.html(diakses pada tanggal 29 Desember 2015)

http://rimalrimaru.com/pengertian-rumah-sakit/(di akses pada tanggal 29 Desember 2015)

Notoatmojo, S. Ilmu Kesehatan Masyarakat, Renika Cipta, Jakarta 2003.

.Metodologi Penelitian Kesehatan, Renika Cipta, Jakarta 2005.

.Pendidikan dan Perilaku Kesehatan. Renika Cipta, Jakarta 2005

Peraturan Menteri Tenaga Kerja Dan Transmigrasi Republik Indonesia Nomor. 08 tahun 2010.

Profil RSUD KRT. SEYJONEGORO Tahun 2015

Undang-undang Nomor 13 Tahun 2003 Tentang Ketenagakerjaan

Undang-undang Nomor 1 Tahun 1970 Tentang keselamatan kerja 